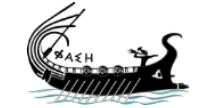 \\ journal.phaselis.org}

\title{
Antikçağ Tiyatrolarında Akustik Üzerine Bir Değerlendirme
}

\section{An Evaluation of Acoustics of Theaters in Antiquity}

\section{Cüneyt Öz}

open 2 access journals

The entire contents of this journal, Phaselis: Journal of Interdisciplinary Mediterranean Studies, is open to users and it is an 'open access' journal. Users are able to read the full texts, to download, to copy, print and distribute without obtaining the permission of the editor and author(s). However, all references to the articles published in the e-journal Phaselis are to indicate through reference the source of the citation from this journal.

Phaselis: Journal of Interdisciplinary Mediterranean Studies is an international peerreviewed journal and the articles which have had their peer reviewing process completed will be published on the web-site (journal.phaselis.org) in the year of the journal's issue (e.g. Volume II: January-December 2016). At the end of December 2016 the year's issue is completed and Volume III: January-December 2017 will begin.

Responsibility for the articles published in this journal remains with the authors.

Citation C. Öz, "Antikçağ Tiyatrolarında Akustik Üzerine Bir Değerlendirme". Phaselis III (2017) 119132 DOI: $10.18367 /$ Pha.17006

Received Date: 27.02.2017 | Acceptance Date: 30.05.2017 | Online Publication Date: 13.06.2017

Editing Phaselis Research Project

www.phaselis.org 


\title{
Antikçağ Tiyatrolarında Akustik Üzerine Bir Değerlendirme
}

\author{
An Evaluation of Acoustics of Theaters in Antiquity
}

\author{
Cüneyt ÖZ*
}

Öz: Antikçağda toplum üzerinde önemli bir yere sahip olan tiyatro sanatı, Hellenlerle birlikte, MÖ VI. ve V. yüzyılda orkestra, theatron (cavea) ve skene (sahne binası) gibi üç ana elemandan oluşan mimari bir yapıya dönüşmüştür. Arkaik Dönem'de orkestra kısmının yapılmasıyla başlayıp, Hellenistik Dönem'de gelişen tiyatro mimarisi nihai ve son şekline Roma Dönemi'nde ulaşmıştır. Hellen ve Roma tiyatroları plan olarak birbirlerinden ayrılan yönlere sahip olsa da, aslında hizmet ettikleri amaç aynıdır. Antik tiyatroların yapımında, dikkat edilerek çözümlenmesi gereken birçok konu varken, akustik de bunlardan bir tanesidir. Tiyatrolardaki akustik, ses ve duyum üzerine kuruludur. Antikçağda, günümüzdeki gibi sesi güçlendirecek ve yayılım hızını artıracak araç gereçlerin kullanımı mümkün olmamıştır. Buna rağmen tiyatrolarda akustiğin geliştirilmesi için birçok yöntem denenmiş ve uygulanmaya çalışılmıştır. Tiyatrolarda akustiğin iyi sağlanması için öncelikle tiyatro yapılacak yerin seçimi önemlidir. Sonrasında caveanın oturtulacağı yamacın eğimi, yapımında kullanılan matematiksel oranlar ve diazomanın yüksekliği, aralarına yerleştirilecek bronz ses küplerinin Aristoksenus'un müzik sistemine göre düzenlenmesi gibi daha birçok konu akustiğin iyileştirilmesine yönelik olarak tiyatrolarda uygulanmaya çalışılmıştır. Tüm bunların yanı sıra sahne binalarının gelişim süreci de tiyatro akustiğine önemli katkı sağlamıştır. Bu makalenin amacı, antikçağ tiyatrolarındaki akustiğin nasıl sağlandığını irdeleyerek, sizlere sunmaktır.

Anahtar sözcükler: Antikçağ, Tiyatro, Ses, Harmoni, Akustik

Abstract: Performing arts, which had an essential role in the societies of antiquity, was transformed into an architectural structure, which consists of orchestra, theatron (cavea) and skene (stage structure) by the Greeks between VI. and V. centuries BC. Architectural form of theatre, which had emerged simply as orchestra in the archaic period, and developed through Hellenistic period, found its final form in the Roman period. Although architectural plans of Greek and Roman theatres vary in some ways, essentially, they both serve the same purpose. Acoustics is one of the many subjects which requires careful consideration in design of ancient theatres. Acoustics in these theatres are arranged based on sound and sense of hearing. Although, unlike today, tools of amplifying sound and its propagation velocity had not been an option, many methods had been tried and employed in order to improve the acoustic quality of theatres. Primarily, site selection for the theater is vital for the acoustic quality of the theater. Apart from this, slope of the hillside on which the cavea stand, arithmetical ratios which are used during the construction process, height of diazoma, the arrangement of bronze acoustic jars amid cavea in accordance with Aristoxenus' musical theory were all carefully assessed and tried in order to improve the acoustic quality in theatres. Additionally, development of the stage building through time had considerably contributed to acoustic quality. This paper aims to examine how acoustic quality of theatres in antiquity was secured.

Keywords: Antiquity, Theatre, Sound, Harmony, Acoustics

* Arş. Gör., Akdeniz Üniversitesi, Edebiyat Fakültesi, Arkeoloji Bölümü, Antalya/TR. cuneyt.oz@outlook.com 
Antikçağda tiyatro kültürü, farklı birçok sanat dalı gibi, kökenini ilkel çağlardaki dinsel tören ve ritüellerden alarak gelişmiş ve zaman içerisinde bağımsız bir sanata dönüşmüştür. Tiyatro ${ }^{1}$, ilk olarak seyirci ve oyuncularla sınırlandırılmıs herhangi bir mekânda oynanan oyun iken, daha sonra sıkıştırılmış toprak tabanlı düz bir alan olan orkestra, bunun etrafındaki yamaçlara yerleştirilen ahşaptan oturma sıralarının (ikria) olduğu theatron ${ }^{2}$ ve yine ahşaptan yalın bir skene yani sahne binasının yer aldığı mimari bir yapıya dönüşmüştür ${ }^{3}$. Kısaca tiyatronun gelişimini Bieber'in şu sözleri ile özetleyebiliriz; "Orkestra Arkaik Çağ'da; theatron, tiyatronun son olgunluğuna eriştiği Klasik Çağ'da (MÖ V. ve IV. yüzyıllar) oluşturulmuştur. Sahneyse (skene), alışılagelmiş biçimini ancak geç Klasik Çağ'da almıştır... Gelişmesi Hellenistik Çağ’da olmuştur. Akılda tutulması gereken en önemli nokta, Klasik Çă̆'da yükseltilmiş bir sahnenin bulunmadığıdır"4. Hellen tiyatrosunu esasen üç ana unsur oluşturmaktadır: Orkestra, theatron (cavea) ve skene (sahne). Hellence "orkhesis" yani "dans edilen bölüm" anlamına gelen orkestra, Hellen tiyatrolarının erken dönemlerindeki en önemli bölümüdür. Ancak Roma tiyatrolarında proskenion ve sahne, orkestranın yerini ele geçirince ${ }^{5}$ orkestranın önemi azalmış ${ }^{6}$, skene orkestradan daha önemli hale gelmiştir ${ }^{7}$. Theatron ise oyuncularla seyircileri buluşturması nedeniyle tiyatroların vazgeçilmez unsurlarındandır. Illk olarak ahşaptan yapılan oturma sıraları, MÖ V. yüzyılın yarısından sonra yerini taştan oturma sıralarına bırakmıştır ${ }^{8}$. Tiyatronun ana unsurlarından üçüncüsü olan skene ise ilk olarak yalın bir yapıdayken, tipik şekline MÖ II. yüzyılda kavuşmuştur ${ }^{9}$. Roma tiyatroları ise Hellen tiyatrolarını model almalarına karşın belirgin farklara sahiptir. Roma tiyatrosu, cavea ve sahne binasını kesintisiz çevre duvarıyla birleştirerek bir araya toplayan, temelde tek bir mimari yapıdan oluşmaktadır ${ }^{10}$. Bu tek yapısal düzenlemeyi sağlayabilmek için cavea ve orkestra yarım daire şeklinde planlanmış ve eski önemi kalmayan orkestra ${ }^{11}$, gösterilerin yapıldığı alan yerine önemli kişilerin oturtulduğu koltukların konulduğu mekân haline gelmiştir ${ }^{12}$. Mimari yapı olarak tiyatronun doğuşunda önemli rol oynayan bu üç ana unsur (orkestra, theatron, skene), yıllar boyu ihtiyaç ve teknik gelişime göre çeşitli mimari eklemelerle onarımlardan geçmiş, günümüze kadar ayakta kalmış olanların halen kullanılabildiği gelişmiş tiyatroların yapılmasına kaynak teşkil etmiştir.

Antikçağdaki tiyatrolar üzerine son yıllarda yapılan akustik incelemeler ${ }^{13}$ dışında, geçmişte

1 Tiyatro kelimesi Hellence'de "seyirlik yeri" anlamına gelen "theatron" sözcüğünden türemiştir (Boyacıoğlu 2004, 206; Knapp 2007, 24).

2 Theatron kelimesinin kökeni hakkında bk. Vovolis 2011.

3 Wycherley 1991, 143-145.

4 Wycherley 1991, 148.

5 Wycherley 1991, 148.

6 Roma Dönemi'nde orkestranın etrafının duvarlarla yükseltilip, hayvan dövüşleri, sirk gösterileri ve gladyatör dövüşlerinde arena olarak kullanıldığı bilinmektedir (Özdilek 2011, 225-226).

7 Er 2012, 404.

8 Wycherley 1991, 152; tiyatrolarda taş kullanımı MÖ V. yüzyılın sonları ile IV. yüzyılda yoğun olarak başlamış (Mutlu 2001, 50; Chourmouziadou - Kang 2008, 515; Er 2012, 403-404), öncesinde ise Doğu Attika'daki Thorikos'ta birkaç kırsal tiyatroda taş kullanımı görülmektedir (Tomlinson 2012, 79; Thorikos tiyatrosunun çizimi için bk. Wycherley 1991, 151, Şek. 44).

9 Tomlinson 2012, 79; Er 2012, 404-405.

10 Thorpe 2012, 76.

11 Thorpe 2012, 76.

12 Thorpe 2012, 76.

13 Yüksel et al. 2005; Irklı-Eryıldız 2006; Knapp 2007; Declercq - Dekeyser 2007; Dragonetti et al. 2007; Barba Sevillano et al. 2008; Chourmouziadou - Kang 2008; Kurtay et al. 2008; Rindel 2008; Vovolis 2009, 2011, 2012; Kontomoichos et al. 2014. 
bu yapıların akustiği üzerine sınırlı sayıda araştırma yapılmıştır. Antik tiyatroların yapımı hakkındaki en önemli başvuru kaynağı Romalı askeri mühendis ve mimar olan Vitruvius'un yazdığı "De Architectura" adlı eserdir. Vitruvius eserinde bir tiyatro inşa edilirken nelere dikkat edileceği konusunda, tiyatronun arazisinden tutun da ses akustiğine kadar birçok bilgi vermiştir $^{14}$. Belki de antik tiyatrolarda akustik üzerine en önemli çalışmalardan birisi, Canac tarafından 1967 yılında yazılan "L'acoustique des Theatres Antiques" adlı kitaptır. Bu kitabın dışında 1900'lü yıllarda yine bu konu üzerine oldukça önemli yazılar yayımlanmışıır ${ }^{15}$. 2003-2006 yıllarına gelindiğinde ise ERATO (Antik Tiyatro ve Odeonların Akustik Mirasının Belirlenmesi, Değerlendirilmesi ve Canlandırılması) Projesi ile birlikte akustik üzerine oldukça kapsamlı bir çalışma yapılmıştır ${ }^{16}$. Bunun dışında İtalya Üniversitesi ve Araştırma Bakanlığı'nın bir projesi olan ATLAS (Antik Tiyatrolarda Aydınlatma ve Akustik Destek) ise akustik üzerine bildiğimiz bir diğer araştırma projesidir ${ }^{17}$. Yukarıda sayılan kaynaklar antikçağdaki tiyatroların akustiği üzerine önemli bilgiler vermektedir. Bu makalede, antikçağ tiyatrolarında akustik için ne gibi materyallerin kullanıldığı ya da akustiğin nasıl sağlandığı konusu etraflıca değerlendirmeye alınarak, okuyucuya sunulmak istenmektedir.

\section{Ses, Harmoni ve Akustik}

Aristoteles'e göre oyunculuk, üç önemli niteliğe sahip olan sese dayalı bir eylemdir ${ }^{18}$. Bu nitelikler; ses, harmoni ve ritimdir. Tüm bu nitelikler özellikle antikçağ tiyatrolarında oynanan oyunlar için oldukça önemlidir.

Ses, hareket halindeki bir cisimden ortaya çıkarak titreşime dönüşmüş, molekül hareketlerinin belirli bir frekans ve şiddet sınıları içinde belirgin hale gelen ve kulağımızda işitme hissi doğuran dalga hareketidir ${ }^{19}$. Titreşim ve hareket ile mümkün hale gelebilen sesten bahsedebilmek için üç temel olgunun olması gerekmektedir; ses kaynağı, ses kaynağının ortaya çıkardığı basınç değişiminin oluşturduğu ses dalgalarını taşıyacak bir iletici ortam ve bu dalgaları algılayacak bir alıcı ${ }^{20}$. Ses, nesnel bir kavram olup, belirli bir ortamda longitudinal basınç dalgaları halinde yayılmaktadır. Küresel yayılım hareketi ile yayılan ses dalgaları, ortamın akustik iletim karakteristiğine bağlı olarak yutulur, yansır, saçılır, kırılır ya da en önemlisi; amaca uygun olarak iletilir $^{21}$. Tiyatrolardaki akustik, ses kaynağından çıkan ses dalgalarının izleyiciye uygun iletiminin sağlanması esasına bağlı, ağırlıklı olarak ses ve duyum üzerine dayalıdır ${ }^{22}$.

Harmoni ${ }^{23}$, müzik biliminin karmaşık ve zor bir birimi ${ }^{24}$ olmasının yanında, farklı yükseklikteki seslerin bir arada duyurulması olarak da tanımlanabilir ${ }^{25}$. Aynı zamanda "bağlantı", "uyum" ve "yapı" anlamına gelen harmoni, Hellenler tarafından evrenin oluşumundan tutun da müzikteki ses dizilerinin oluşmasının açıklanmasına kadar geniş bir anlamda kullanılmışıı ${ }^{26}$. Sesleri dikey

14 Vitr. de Arch. V.

15 Yayınlar hakkında ayrıntılı bilgi için bk. Irklı-Eryıldız 2006, 284.

16 Ayrıntılı bilgi için bk. Yüksel et al. 2005, 1-8; Haddad 2008.

17 Barba Sevillano et al. 2008, 4156; Dragonetti et al. 2007.

18 Kontomoichos et al. 2014, 1445.

19 Aykol 1986, 25.

20 Çetinkaya 2010, 1; Baysal 2015, 1351.

21 Sabah 2013, 52-53.

22 Chourmouziadou - Kang 2008, 527.

23 Mitolojisi için ayrıca bk. Grimal 2012, 69.

24 Vitr. de Arch. V. IV.

25 Waugh 2000, 34.

26 Polat 2012, 64; Ancak Pythagoras ve Platon, gezegenlerin birbirleriyle olan harmonisi için akroasis terimini kullanmıştır. Bk. Vovolis 2012, 151. 
yaklaşımla ele alan harmoni, aynı anda birden fazla duyurulmak istenen sesin, birbirleri üzerine bindirme şekillerini ve dikey ses gruplarının birbirleriyle olan bağlantılarını incelemektedir ${ }^{27}$. Çoksesliliğin temeli olan akorların kuruluşları, bağlanışları, çevirimleri ve yürüyüşleri ile de harmoni ilgilenmektedir ${ }^{28}$. Antikçağda yapılan tiyatro oyunlarında kullanılan müzik aletleri ve oyuncu sesleri arasındaki uyum önemlidir. Çünkü müzik aletlerinden çıkan yüksek ses oyuncuların seslerini bastırabilir. Bu yüzden bu iki farklı sesin birlikte bir uyum sağlaması harmoni biriminin öncelikli amaçları arasında sayılabilir.

Akustik, "işitmek ile ilgili" Hellence "ákouбtıkós" (akoustikos) sıfatından Türkçe'ye geçmiş$\operatorname{tir}^{29}$. Ses dalgalarının oluşumu ile yayılmasını, fiziksel ve fizyolojik açıdan inceleyen akustik, mekanik biliminin alt dalıdır ${ }^{30}$. Akustik, gürültü denetimi ve hacim akustiği olarak iki temelde incelenmektedir. Mimari akustik içerisinde geçmişi en eski olan hacim akustiği, eski çağlardan beri incelenen bir konudur. Hellen tiyatroları ise hacim akustiğine gösterilen ilk örnekler arasında sayılabiliir ${ }^{31}$. Mekânın akustiğini ölçmek için, akustik analiz yöntemlerinden birini kullanmak ve bunların sonuçlarını bir dizi matematiksel hesaplamadan geçirmek gerekmektedir ${ }^{32}$.

\section{Antikçağ Tiyatrolarında Akustik}

Tiyatronun mimari bir yapı biçimi olarak ilk ortaya çıkışı, nasıl yapııdığı ve yıllar içerisinde gelişiminin nasıl gerçekleştiği konusu gibi sorular birçok araştırmacı tarafından düşünülmüş, sorgulanmış ve bu konular üzerine sayısız tez ve yayın yapılmıştır. Fakat bu yapılarda akustiğin nasıl sağlandığı konusu son yıllarda yazılan makale ${ }^{33}$ ve yapılan projeler ${ }^{34}$ dışında, oldukça az sayıda araştırmaya konu olmuştur.

Tiyatroların akustiği hakkındaki ilk bilgilerimizi Vitruvius'un De Architectura kitabının beşinci bölümünde verdiği, tiyatrolardaki akustik kaliteyi sağlamaya yönelik önerilerinden edinmekte$\mathrm{yiz}^{35}$. Buna göre, öncelikle tiyatro yapımında yankılanma engeliyle karşılaşmadan yumuşak bir biçimde sesi kulağa kadar getirecek bir arazi seçimi yapılmalıdır. Kalkışmalılar (dissonant), circumsonantlar, seselimliler (rezonant) ve sessizler (consonant) olarak bilinen yerler sesin dağılmasını önlemekte olduğu için tiyatro yapımına uygun olmayan arazilerdir ${ }^{36}$. Kalkışmalılar, ağızdan çıkan ilk sesin yükselerek yukarıda herhangi bir yere çarpıp geri geldiğinde, aşağı inerken kendini izleyen sesi engellediği yerler olarak tanımlanmaktadır ${ }^{37}$. Circumsonant arazilerdeki ses alana yayıldıktan sonra ortada kısııı; hâl takıları duyulmazken anlamca belirsiz seslerle birlikte kaybolmaktadır. Seselimli arazide sert bir nesneyle karşılaşan ses geri çekilirken yankılanır ve sesteki hâl takılarının çift olarak duyulmasına neden olur ${ }^{38}$. Sessizlerde ise ses aşağıdan

27 Sağer - Sevgi 2011, 24.

28 Çevik et al. 2012, 71.

29 Çelgin 2011, 35 s.v. ákouøtıkós.

30 Çetinkaya 2010, 1.

31 Erol 2006, 1, 25.

32 Kurtay et al. 2008, 558.

33 Yüksel et al. 2005; Irklı-Eryıldız 2006; Knapp 2007; Declercq - Dekeyser 2007; Dragonetti et al. 2007; Barba Sevillano et al. 2008; Chourmouziadou - Kang 2008; Kurtay et al. 2008; Rindel 2008; Vovolis 2009, 2011, 2012; Kontomoichos et al. 2014.

34 ERATO ve ATLAS projeleri için bk. Yüksel et al. 2005, 1-8; Dragonetti et al. 2007; Barba Sevillano et al. 2008, 4156.

35 Vitr. de Arch. V.

36 Vitr. de Arch. V. VIII. 1.

37 Vitr. de Arch. V. VIII. 1.

38 Vitr. de Arch. V. VIII. 2. 
desteklenmekte yukarı çıktıkça kulağa berrak ve tonu belirgin sözcükler olarak ulaşmaktadır ${ }^{39}$. Hareketli bir hava olan ses, dokunulduğunda algılanabilmektedir. Ses, tıpkı suya atılan taşın su yüzeyinde yaptığı konsantrik dalgaların herhangi bir engelle karşılaşıncaya kadar büyüyerek devam etmesi gibidir ${ }^{40}$. Dalgalar halinde yayılan ses herhangi bir engelle karşılaştığında ona çarparak geri döner. Döndüğünde ise arkasından gelen diğer ses dalgalarını kırmaktadır ${ }^{41}$. Eğer herhangi bir engele çarpmadan devam ederse, arkadaki ses dalgaları da onu takip eder. Yankılanma olmadığı sürece ses tiyatroda en altta ve en üstte bulunan izleyicilere sorunsuz bir şekilde ulaşacaktır ${ }^{42}$.

Antikçağda mimarlar, tiyatrolarda akustiği sağlamak için arazinin yapısı, oturma sıralarının eğimi ve çapı, sesin tiyatro içerisindeki yayılımı ile tiyatronun her yerinde sesin aynı berraklıkta duyulması için birçok alanda yapılan çalışmalarla da ilgilenmişlerdir. Örneğin, müzik ve matematik bilimcilerin geliştirdikleri kanon kuramı ${ }^{43}$. Vitruvius, tiyatrolarda sesin üst oturma sıralarına kolaylıkla erişmesi için ses yansıtıcı olarak kullanılan bronz küplerin varlığından söz etmektedir ${ }^{44}$. Bu bronz küplerin müzikteki kanon kuramına göre yerleştirildiği ve ciddi matematiksel ilkeler üzerine kurulduğu söylenmektedir ${ }^{45}$. Bunlar, tiyatro oturma sıralarının aralarında belirli bir düzende açılacak olan nişler içerisine, müzik yasalarına göre (Vitruvius, küpleri tiyatrolarda yapılan nişlere yerleştirirken, Aristoksenus'un müzik sistemini (tetrachord) temel alıp ${ }^{46}$, her küpe farklı notalar atfedilmesi gerektiğinden bahsetmektedir ${ }^{47}$ ), nişin hiçbir duvarına değmeyecek biçimde ters olarak yerleştirilmelidir ${ }^{48}$. Bu nişlerin üstlerinde ve orkestraya bakan yüzlerinde açıkıklar olmalıdır ${ }^{49}$ ki küplere çarpan ses kolaylıkla tiyatronun üst oturma sıralarına tekrardan oluşan bir ses dalgası şeklinde yayılabilsin. Tiyatroya koyulan bu boyları ve formları farklı kapların her biri, farklı tonlarda notalar vermekte ve tiyatro içerisine yansıttıkları alçak ya da yüksek ses tonları dikkate alınarak müzikal harmoniye göre yerleştirilmektedirler ${ }^{50}$. Oyuncunun sesi bu kaplardan herhangi biriyle aynı perdeden olduğunda, ses kuvveti artar ve dinleyicinin kulağına daha pürüzsüz ve tatı bir tonda ulaşır ${ }^{51}$. Ne yazık ki bugüne kadar arkeolojik kazılarda bu tür

39 Vitr. de Arch. V. VIII. 2; Sabine 1922, 163-164.

40 Vitr. de Arch. V. III. 6.

41 Vitr. de Arch. V. III. 6.

42 Vitr. de Arch. V. III.

43 Vitr. de Arch. V. III; Hellence'de kamış ve saz anlamındaki "kanna" sözcüğüyle ilintili olarak, birbirine geçirilmiş kamışlardan yapılan örtü, sepet ve çatıyı anlatmak için kullanılmış sözcüklerden türeyen "uzun ve düz ağaçtan sırık ya da sopa" anlamına gelen "kanon" terimi (Çelgin 2011, 346) ilk olarak mimaride karşımıza çıkmaktadır (Baysal 2015, 1352). Kanon, MÖ V. yüzyılda Pisagorcuların harmoni düşüncesinden yola çıkan heykeltıraş Polykleitos'un yazdığı kitabın başlığında kendine yer bulmuştur. Polykleitos, bu kitabında heykel yapımının kurallarını ortaya koyarken kanon sözcüğüne estetik bir anlam yüklemiştir. Bu anlamda bakıldığında bu sözcük aynı zamanda ideal bir estetiğin "kanunu" ve "kuralı"dır. MÖ III. yüzyılda yaşamış olan Oklid'in olduğu düşünülen makalede ise kanon, oransal olarak düzen yanında müzikal düzeni de anlatan bir kelime olarak ifade edilmiştir (Baysal 2015, 1352-1353). Kısaca kanon, iki sesin belirli aralıklarla tekrarı olarak tanımlanabilir (Yılmaz 2010, 18, dn. 17).

44 Vitr. de Arch. V, V.

45 Vitr. de Arch. V, V; Yılmaz 2010, 18.

46 Vitr. de Arch. V.IV.

47 Bk. Vitr. de Arch. V. V. 1.

48 Barba Sevillano et al. 2008, 4155-4160.

49 Vitr. de Arch. V. V. 1.

50 Vitr. de Arch. V. V.

51 Vitr. de Arch. I. I. 9. 
küplere rastlanılmamıştır. Yılmaz ${ }^{52}$, Selge Tiyatrosu'ndaki diazomanın arkasında bulunan duvarın içindeki beş adet yuvanın bu küplere ait olabileceğinden bahsetmektedir ${ }^{53}$. Bir diğer araştırmacı olan Izenour ${ }^{54}$, Beth Shean Tiyatrosu'nda (İsrail) bu tarz küplerin yuvaları olabilecek kalıntıların varlığından söz etmektedir ${ }^{55}$. Ancak ona göre bu küplerin akustiğe etkisi oldukça zayıftır. Termessos, Perge ve Aspendos tiyatrolarının akustiğini temel alarak antik tiyatroların akustiğini inceleyen Eryıldız ise, Aspendos tiyatrosunda bulunan nişlerin diazomanın arkasındaki galeriyi aydınlatma amacı taşıyabileceğinin yanı sıra, aynı zamanda ses küpleri için de kullanılmış olabileceğini aktarmaktadır ${ }^{56}$. Vitruvius, bu bronz küplerin Roma'da değil aksine Hellen kent devletlerinde yoğun olarak kullanıldığını dile getirmektedir ${ }^{57}$.

Tiyatrolarda akustiği sağlamak için oturma sıralarının yapımı önemlidir ${ }^{58}$. Oturma sıralarının çapı ve tiyatro caveasının oturtulduğu yamacın eğimi, tiyatro içerisinde oluşacak sesin şiddetiyle bağlantılıdır ${ }^{59}$. Orkestradan gelen seslerin seyircilere daha iyi yansıması için, tiyatro oturma sıraları genelde $20-34^{\circ}$ lik açıyla konumlandırılmaktadır ${ }^{60}$. Bir başka görüşe göre, oturma sıraları diazoma öncesinde $30^{\circ}$, diazomadan sonra ise $38^{\circ}$ lik (bu derece farkının Roma tiyatrolarındaki diazomadan sonra üst oturma sıralarına geçişteki yükseklikle ilintili olabileceği düşünülebilir ${ }^{61}$ ) bir açıyla konumlandırılırsa, tiyatro akustiği açısından olumlu sonuçlar verecektir ${ }^{62}$. ERATO projesi kapsamında Sicilya'da bulunan Syrakousai antik kenti tiyatrosu ile Ürdün'de yer alan Jerash antik kentindeki güney tiyatroda yapılan akustik ölçümlerde Syrakousai Tiyatrosu'na göre cavea çapı daha küçük olan Jerash Tiyatrosu'nda ses şiddetinin daha yüksek olduğu görülmektedir ${ }^{63}$. Buna göre cavea çapının büyük olması akustik açıdan bir dezavantaj olarak düşünülebilir $\mathrm{mi}^{64}$ ?

52 Yılmaz 2010, 18, 172.

53 Yılmaz'ın burada yaptığı varsayımın herhangi bir kanıtı bulunmamaktadır. Bu yuvalar aydınlatma ya da statik amaçlı da yapılmış olabilir.

54 Barba Sevillano et al. 2008, 4160, Fig. 13.

55 Bu tiyatro dışında Gerasa Tiyatrosu (Ürdün) ile Skythopolis antik kenti tiyatrosunda da bu tür nişlere rastlanmıştır (Barba Sevillano et al. 2008, 4160).

56 Irklı-Eryıldız 2006, 283.

57 Vitr. de Arch. V. V.

58 Epidauros Tiyatrosu'nun caveası yapılırken matematiksel hesaplamalardan yararlanılarak yapıldığı ileri sürülmektedir. Bk. Vovolis 2012; Fossum 1926. Tiyatronun oturma sıra sayılarının (34-21, 55-34) arasındaki uyumun, Pythagoras'ın altın oranı ya da Fibonacci sayıları (bu sayılar ve altın oran hakkında bk. Bakım 2014, 2-9) ile ilintili olduğu söylenmektedir. Caveanın bu matematiksel ve geometrik hesaplamalarla kurulmasının akustiği iyileştirdiği düşünülür (Vovolis 2012, 153).

59 Rindel 2008, 33; Özdilek 2011, 31.

60 Yaşaroğlu 2006, 8; Hellenistik Dönem tiyatrolarında caveanın oturtulduğu yamacın eğimi çeşitli morfolojik özelliklere göre artabilir, hatta 40inin üstüne de çıkabilir. Oturma sıraları için verilen ortalama ölçüler + - 3/5 cm. arasında değişebilir (Özdilek 2011, 29); Anadolu'da incelenen birçok tiyatroda oturma sıraları yaklaşık $30^{\circ}$ eğimle yapılmıştır (Yılmaz 2010, 17); Anadolu'da bulunan tiyatrolar hakkında ayrıntılı bilgi için bk. Dilmen 2004, 13-34.

61 Ayrıca Roma tiyatrolarında ima cavea'nın eğimi, summa cavea'ya göre daha azdır. Summa cavea'nın eğiminin fazla olması akustik ile orkestra'ya bakışın iyileştirilmesi amacına yöneliktir (Özdilek 2011, 29).

62 Irklı - Çalışkan 1990, 356.

63 Rindel 2008, 33, Tab. 1.

64 Tiyatro planı hakkında bk. Vitr. de Arch. V. VI-VII. Elbette ki cavea çapı tek başına düşünülemez; cavea, sahne binası ve her ikisini birleştiren yan duvarların bütünleyici rolü akustiğin daha iyi olmasını sağlayan faktörlerdir (Özdilek 2011, 31). Ancak sahne binası, orkestra ve caveanın orantısız ölçülerde olmasının da akustiği etkileyeceği göz önünde bulundurulmalıdır. Şöyle ki Vitruvius, Roma tiyatrolarında sesin üst oturma sıralarına daha rahat ulaşması için caveanın arka bitimine yapılacak revakların çatı yüksekliği ile sahne binasının yüksekliğinin eşit olması gerektiğinden bahsetmektedir (Vitr. de Arch. V. VI. 4). Ayrıca bk. Declercq - Dekeyser 2007a. 
Özellikle Hellenistik Dönem tiyatrolarında caveanın uç kısımlarının sahneye uzatılarak at nalı formu almasının, aslında dinleyicilere sesin berrak ve anlaşılır bir şekilde ulaştırılmak istenmesinden kaynaklı olabileceği söylenmektedir ${ }^{65}$.

Tiyatroda oturma sıralarını yatay olarak ayıran geçiş veya gezinti yerlerinin (diazoma) genişliği ve yüksekliği oransal olarak eşit olmalıdır ${ }^{66}$. Eğer bu geçitler yüksek olursa orkestradan gelen sesi yansıtarak sesin üst kısımlara ulaşmasını engeller, farklı yönlere dağılan ses ise üst sıralarda oturan kişilere tam anlamıyla ulaşamayacaktır ${ }^{67}$. Işte bundan dolayıdır ki oturma sıraları yapııırken orkestradan yukarıya doğru çizilecek düz bir hat hiçbir engele takılmadan en üst noktaya kadar ulaşırsa, seste aynı şekilde en üst oturma sıralarına kadar sorunsuzca ulaşacaktır ${ }^{68}$.

Güneşten korunmak için kullanılan baldeken/velum ${ }^{69}$ (yelken, perde, tente, gölgelik) dışında üzerlerinin açık olduğu bilinen antik tiyatrolarda rüzgâr ve yağmur gibi doğa olayları tiyatrodaki akustiği olumsuz etkileyen faktörlerdendir ${ }^{70}$. Vitruvius kitabında, tiyatroların rüzgârlara karşı korunakıı bir biçimde yapılması gerektiğini söylemektedir. Çünkü bataklık gibi alanlar üzerinden eserek gelen rüzgâr tiyatroya ulaştığında insanları rahatsız ederek ${ }^{71}$, oyuncuların seslerini dağıtıp, sesin tiyatro içinde herhangi bir yerde boğulmasına sebebiyet verebilir. Sahne binasının intişamlı görünümüne kavuşmadığı erken dönem tiyatrolarında orkestranın arkasından oturma sıralarına doğru esen rüzgârın, sesin taşınmasında etkin bir rol üstlenmiş olabileceği düşünülür ${ }^{72}$. Böylece oyuncuların sesini izleyiciye taşıyan rüzgâr, önemli bir akustik görev üstlenmiştir. Sahne binalarının oldukça görkemli bir yapıya dönüştüğü Roma Dönemi'nde ise bunların dışarıdan gelecek gereksiz sesleri engelleyen bir kalkan ya da koruma duvarı işlevinin yanı sıra orkestrada ya da logeion/pulpitumda performans sergileyen oyuncuların seslerini yansıtma görevi gördüğü de düşünülmektedir ${ }^{73}$. Ayrıca sahne binalarının üzerine yapılan ahşap çatı da oyuncuların sesini yansıtarak, akustik anlamda fayda sağlamıştır ${ }^{74}$. Hunningher, sahne binası yıkık olan Syrakousai Tiyatrosu ile sahne binasının büyük bir kısmının ayakta olduğu Tauromenion Tiyatrosu'nu karşılaştırmış ve Tauromenion Tiyatrosu'nun ses uyumunun daha iyi olduğunu tespit ederek, tiyatrolarda yapılan sahne binalarının öncelikli yapım amacının akustiği geliştirmek olduğunu ileri sürmüştür ${ }^{75}$. Elbette ki tiyatrolarda yapımına başlanmasıyla birlikte sürekli değişen ve gelişen sahne binaları ${ }^{76}$, doğrudan veya dolaylı olarak tiyatro akustiğine katkı sağlamıştır.

Roma tiyatrolarında seyircileri güneşten korumak için yapılan velumun ses yansıtıcı özelliğe sahip olduğu, aynı zamanda yankılanmayı önlediği düşünülmektedir ${ }^{77}$. Antikçağ tiyatrolarında

65 Özdilek 2011, 31.

66 Vitr. de Arch. V. III. 4.

67 Vitr. de Arch. V. III. 4.

68 Vitr. de Arch. V. III.

69 Karatağ 2013, 416; ayrıca bk. Özdilek 2016, 159.

70 Rindel 2008, 32.

71 Vitr. de Arch. V. III.

72 Epidauros Tiyatrosu’nda orkestradan caveaya doğru esen rüzgârın sesin taşınmasını sağladığı düşünülmekte, fakat rüzgâr esmediğinde de tiyatronun akustiğinin iyi olduğu görülmektedir (Declercq - Dekeyser 2007a, 2012); Bilindiği gibi tiyatroların yön ve konumu birçok koşulun yanında (Özdilek 2011, 28) güneş ve rüzgâr dikkate alınarak seçilmiştir. Bk. Vitr. de Arch. V. III; Ferrero 2009, 28.

73 Vovolis 2012, 151; Özdilek 2011, 31-32.

74 Thorpe 2012, 76-77.

75 Vovolis 2012, 152, dn. 6.

76 Sahne binalarının gelişimi için bk. Özdilek 2011, 232 vd.

77 Yaşaroğlu 2006, 12; Aspendos Tiyatrosu'nda güneşten korunmak için yapılan gölgeliğin yün olduğu 
kullanılan velumun aslında güneşten korunmak için yapıldığı bilinse de aynı zamanda tiyatro akustiğine katkı sağlamış olabileceği söylenebilir ${ }^{78}$. Çünkü Aspendos Tiyatrosu'nun günümüzdeki mevcut durumda üstü açıkken yapılan akustik ölçümlerinde, tiyatronun seslilik değerinin ${ }^{79}$ düşük olduğu görülmüştür ${ }^{80}$. Ayrıca aynı ölçümlerde konuşmanın anlaşılabilirliği de (kapalı ortamlarda \%70-75 daha iyi anlaşılabilirdir) \%60 orta anlaşılabilir çıkmıştır ${ }^{81}$. Hiç şüphesiz tiyatro üst kısmının açık olması bu değerleri etkilemiştir.

Kentlerin kuruluşunda bölgeye yakın olan taş ocakları kullanıldığı için kentte bulunan yapılarda da yörede ne tür taş çeşidi varsa o kullanılmıştır ${ }^{82}$. Fakat mermer kullanılmak istendiğinde, önemli mermer ocaklarından büyük bloklar yarı işlenmiş şekilde taşınmış ve mimariye uygun işlenerek yapılardaki yerini almışıı ${ }^{83}$. Bazı kayaçlar özellikleri gereği sert (mermer vb.) olurken, bazıları daha gözenekli ve yumuşak (kireç taşı, traverten vb.) yapıdadır. Yumuşak ve gözenekli maddelerin sesi yutarak yankılanmayı azalttığı bilindiğinden ${ }^{84}$, bazı tiyatrolarda kullanılmış olan kireçtaşı blokların ${ }^{85}$ sesi emerek, yankılanmayı azaltmış olabileceği düşünülebilir. Yankılanmanın azalmasıyla tiyatrodaki akustiğin daha iyi hale gelmiş olması ve sesin algılanışının iyileşmesi beklenebilir bir durumdur. Üzeri oluklu veya dalgalı olan taşların (kireçtaşı vb.) yüzeyinden sesin kayma/akış hızının yüksek olduğu, dolayısıyla bu çeşit taşların kullanıldığı tiyatro içerisindeki sesin daha çabuk yayıldığı düşünülmektedir. Örneğin; Epidauros Tiyatrosu'nun yaklaşık 2000 $\mathrm{kg} / \mathrm{m}^{3} l u ̈ k$ bölümünün gözenekli kireçtaşından yapıldığı bilinmektedir ${ }^{86}$. Tiyatroda yapılan ses ölçümlerinde, kireçtaşından yapılan oturma sıralarının da etkisiyle, sesin kırılarak yayılımının oldukça hızlı ve yüksek olduğu ortaya konulmuştur ${ }^{87}$. Aynı zamanda tiyatrolarda kullanılan sert kayaçların ise sesi ahşaptan daha iyi yansıttığı için ${ }^{88}$ sesin seyircilere ulaşmasında ve tiyatro içerisine yayılmasında etkili olduğu bilinmektedir. İlk olarak sıkıştırılmıs topraktan yapılan orkestra zemini daha sonraki dönemlerde, farklı birçok nedenin yanında, akustiği iyileştirmek amacıyla sesi yansıtması için mermerden yapılmaya başlanmışıı ${ }^{89}$.

Çoğunlukla Roma tiyatrolarında en üst oturma sıralarından sonra yapılan üzeri kemerli galerilerin (revak) çatı kısmının, sesin çatıya ve en üst oturma sıralarına eşit güçte yükselebilmesi

söylenmektedir (Rindel 2008, 33).

78 Akustik üzerine 19. yüzyılda yapılan birçok araştırmada bir evin odasına yerleştirilen ağır kumaş perdelerin yankılanmayı önlediği ortaya konmuştur (Eagleson 1940, 38). Bu örnekten hareketle tiyatrolarda kullanılan gölgeliklerin sesin yankılanmasını azaltmış olabileceği düşünülebilir.

79 Seslilik değeri, ses kaynağının toplam ses basınç düzeyi ve ses gücü düzeyleri arasındaki farktır (Dilmen 2004, 76).

80 Dilmen 2004, 76.

81 Dilmen 2004, 76. Aspendos Tiyatrosu'nun akustik özelliklerinin kusursuz olmadığı, fakat birçok akustik parametrelerinin olumlu sonuçlar verdiği de bir gerçektir. Bk. Dilmen 2004, 77. Antik tiyatroların günümüzdeki mevcut durumunda yapılan akustik ölçümleri, tiyatronun orijinal akustik değerlerini birebir vermemekte, sadece yapıldığı dönemdeki akustiği hakkında göreli bilgi sahibi olmamızı sağlamaktadır.

82 Özdilek 2011, 263.

83 Bingöl 2012, 100.

84 Eagleson 1940, 37.

85 Hierapolis Tiyatrosu'nda kalker ya da traverten, Heraklea Latmos, Alinda ve Alabanda da yerel granit, Priene ve Pergamon tiyatrolarında ise oturma sıralarının kaplanmasında mermer ve ince kalker kullanılı̆̆ını örnek gösterebiliriz (Ferrero 2009, 36).

86 Declercq - Dekeyser 2007a, 2012.

87 Araştırma, sesin her frekans için, Epidauros Tiyatrosu'nun oturma sıralarıyla etkileşime girdiğinde nasıl davrandığı ve akustikte oturma sıralarının önemi üzerinedir. Bk. Declercq - Dekeyser 2007a; Declercq Dekeyser 2007b.

88 Chourmouziadou - Kang 2008, 527.

89 Vovolis 2012, 152. 
için sahne binasının yüksekliği ile aynı hizada olması gerekmektedir. Eğer çatı yüksek değil de alçaksa, alçaklığı oranında sesin dağılımını engelleyecektir ${ }^{90}$. Engellenen ses ise üst oturma sıralarındaki izleyicilere ulaşamayarak, akustik açıdan sorun yaratacaktır.

Diğer tiyatrolarla karşılaştırıldığında erken Klasik Dönem tiyatrolarında sesin yankılanma süresinin kısa ve yansımasının yetersiz olduğu bilinmektedir ${ }^{91}$. Erken Klasik Dönem'den Hellenistik Dönem'e tüm tiyatrolarda sesin düzeyi ve yankılanma seviyesinin yükseldiği görülmektedir (aşırıya kaçan ses yankılanma süresinin akustik açıdan kötü sonuçlar doğuracağı da unutulmamalıdır). Bu durum tiyatroların akustik fonksiyonlarının giderek daha da geliştiğinin göstergesi olarak çözümlenebilir². Roma tiyatrosunun planı Hellenistik tiyatrolara göre daha kapalı bir forma sahiptir. Böyle bir plan tipi Roma tiyatrolarında sesin yankılanma süresinin daha uzun olmasına neden olmaktadır ${ }^{93}$. Aspendos Tiyatrosu'nda olduğu gibi, genellikle Roma tiyatrolarında var olan oturma sıralarının bitimindeki sütunlar üzerine oturan kemerlerle oluşturulmuş galeriler ve sahne binasının yüksek duvarlarının sesin yankılanma süresini uzattığı, son yıllarda yapılan ölçümlerle de kanıtlanmışıı ${ }^{94}$. Roma tiyatrolarında, tiyatro boş iken yapılan ölçümlerde sesin yankılanma süresinin daha uzun, dolu iken ise neredeyse modern tiyatrolar kadar akustiğinin iyi olduğu görülmüştür ${ }^{95}$. Bu durum tıpkı günümüzde bir evin boş salonunda konuştuğunuzda sesinizin yankı yapması, aynı salonun mobilyalarla dolu olduğunda yaptığınız konuşmada ise hiçbir yankılanma duyulmamasına benzemektedir. Ancak Aspendos Tiyatrosu'nda seyirciler varken yapılan akustik ölçümlerde ses hızının azaldığı görülmektedir ${ }^{96}$. Ses hızının azalmasıyla birlikte sesin dinleyiciler tarafından daha berrak algılanması, tiyatrolardaki akustik özelliklerin geliştirilmesi amacına hizmet etmektedir ${ }^{97}$. Çünkü tiyatrolarda oynanan oyunlarda sesin berraklı̆̆ı ve iyi algılanabilirliği son derece önemlidir.

Bazı araştırmacılar tiyatrolarda oynanan oyunlarda aktörlerin taktığı maskelerin ${ }^{98}$ megafon görevi yaparak sesin seyirciye duyurulmasına yardım etmiş olabileceğini düşünmektedir ${ }^{99}$. Maske takmış oyuncudan çıkan seste anlaşıımaz bir yankılanma olmamaktadır ${ }^{100}$. Çünkü bu ses consonant (sessiz) özelliğe sahip olduğu için izleyicinin kulağına berrak ve temiz bir şekilde ulaşır. Maskelerin akustik açıdan herhangi bir işlev taşıyıp taşımadıkları son yıllarda fazlasıyla araştırılıp, tartışılmaktadır. Bir araştırmada ${ }^{101}$, arkeolojik buluntulara göre aslına uygun yeniden hazırlanan iki farklı mask cansız mankenlere giydirilerek, çeşitli ses ölçümleri yapılmıştır (masklardan ilki cansız mankenin tüm kafasını sararken (kulaklarda dâhil) diğeri sadece başı kapatmakta, kulakları ise açıkta

90 Vitr. de Arch. V. VI. 4.

91 Chourmouziadou - Kang 2008, 527.

92 Chourmouziadou - Kang 2008, 527.

93 Chourmouziadou - Kang 2008, 527.

94 Bk. Rindel 2008.

95 Chourmouziadou - Kang 2008, 527.

96 Rindel 2008, 34-35, Fig. 3.

97 Rindel 2008, 41.

98 Klasik Dönem boyunca Hellenlerde mask kelimesini ifade etmek için prosopon terimi (bu kelime MÖ IV. yüzyııın ikinci yarısında ilk defa Theofrastos'un Karakterler kitabında "prosopeion" olarak görülür) kullanılmaktaydı. Bu kelime aynı zamanda insan yüzünü ifade etmek için de kullanılmıştır. Çünkü Hellenlerde insanın zihinsel evreninde maske ile yüz arasında hiçbir ayrım yoktur (Vovolis 2009, 31-32; Vovolis 2012, 159).

99 Barba Sevillano et al. 2008, 4156. Elde var olan belgelerin çoğu, tam olarak baş kısmına uygun maskın ilk takıışını MÖ V. yüzyıl sonları olarak işaret etmektedir. Thespis'in öğrencisi Phrynichos tarafından tanıtılan ilk mask ise bir kadın maskıdır (Vovolis 2009, 32).

100 Vovolis 2012, 167.

101 Kontomoichos et al. 2014, 1444-1452. 
bırakmaktadır $\left.{ }^{102}\right)$. Buna göre antikçağ tiyatro masklarının, aktörün sesinin yayılımını önemli ölçüde yükselttiği sonucuna varılmıştır ${ }^{103}$. Daha sonra aynı mankenler Epidauros Tiyatrosu'nun orkestrası ile proskeniona yerleştirilerek, tiyatroda ayrı bir ses ölçümü daha yapılmışır. Bunun sonucunda, özellikle gürültülü koşullar altında, oyunu izleyen seyircilerin masklar sayesinde aktörün sesini algılamalarının daha iyi olduğu anlaşılmıştır. Ancak maskların, normal koşullar altında, Epidauros Tiyatrosu'nun akustiğindeki mükemmel anlaşılabilirliğinin üzerine etkisinin bulunmadığı sonucuna varılmıştır ${ }^{104}$. Araştırmada özellikle gürültülü koşullar altında maskeli aktörlerin sesinin daha iyi anlaşılması sonucu şaşırtıcı ve ilginçtir. Belki de bu sonucun maskeden çıkan sesin consonant özelliğinden kaynaklı olmasıyla ilişkisi vardır. Bazı sesli harfler (i, e) yüksek frekanslıyken, bazıları $(a, 0)$ ise düşük frekanslıdır. Fakat birçok sessiz harf (d, b, v, z, l, m, n, r) yüksek frekanslı olma özelliğine sahiptir. Yüksek frekans özelliğine sahip olan sesli harfler büyük ve geniş alanlarda gereklidir. Tiyatroda oynanan birçok oyunda, konuşmanın daha iyi anlaşılabilmesi için yüksek frekansa sahip olan sesler (birçoğu sessiz yani consonant) büyük önem arz etmektedir ${ }^{105}$

\section{Değerlendirme}

Antikçağda tiyatro, birçok oyun yazarının katkılarıyla gelişirken, mimari form olarak inşa edilen tiyatro da bunlara paralel olarak birtakım eklemeler ve düzenlemelerle birlikte son özgün şekline Roma Dönemi'nde kavuşmuştur. Nereye yapılacağından tutun da iyi bir akustik için nelerin yapılacağına kadar birçok araştırma ve bilginin sonucunda tiyatrolar inşa edilmektedir. Antikçağ tiyatrolarındaki akustik son derece önemlidir. Çünkü günümüzdeki gibi sesi güçlendirerek yayılımını hızlandıracak araç gereçlerin kullanımı mümkün olmamıştır. Bu yüzden insanoğlu tiyatrolarda akustiği geliştirmek için birçok yol ve yöntem denemiştir. Bunlardan ilki tiyatro yapılacak arazinin akustik açıdan uygun olmasıdır. Dissonant, circumsonant, rezonant ve consonant özelliğe sahip araziler, sesin dağılmasını önlediği için tiyatro yapımına uygun değildirler. Arazi seçimi yapıldıktan sonra cavea, ses akış hızının hareketine uygun olarak, belirli bir eğim sağlayan yamaca oturtulmalıdır. Tiyatronun yapıldığı yamacın eğimi ve caveaların diazomalarla bölünmesi gibi etkenler caveaların eğim oranını etkilemektedir. Örneğin Roma tiyatrolarında imma cavea ile summa caveanın eğim oranı eşit değildir. Bu hem summa caveanın orkestraya bakış perspektifinin uygun olarak sağlanmasına hem de diazomanın yüksekliği ile akustik değerlerin daha iyi sağlanması amacına yöneliktir. Antik tiyatrolarda sahne binalarının da akustik açıdan olumlu sonuçlar için kullanıldığı bilinmektedir. Her ne kadar ilk olarak dışarıdan gelen gereksiz sesleri engelleyen bir kalkan görevi görmüş olsa da, bazı araştırmacılar sahne binalarının ilk yapılış amacının akustiği geliştirmek olduğunu savunmuştur ${ }^{106}$. Hiç kuşkusuz tiyatro akustiğine önemli katkısı olan sahne binalarının ilk olarak akustiği geliştirmek için yapıldığı fikri pek makul değildir. Çünkü ilk olarak ahşaptan bir paravanı andırır şeklinde yapılan sahne binaları, oyuncuların giysilerini değiştirmek ve oyun esnasında gerekli hazırlıkları yapmak için kullandıkları alanlar olarak görülmektedir. Ayrıca sahne binaları, oyunlarda oyuncuların arkasında görsel bir fon yaratmak için de kullanılmışlardır.

Sesin longitudinal basınç dalgaları şeklinde tiyatro içerisinde rahatlıkla hareket etmesi ve

102 Bk. Kontomoichos et al. 2014, 1445, Fig. 3.

103 Kontomoichos et al. 2014, 1446.

104 Kontomoichos et al. 2014, 1451.

105 Vovolis 2012, 168.

106 Bk. Vovolis 2012, 152, dn.6. 
yayılması için, müzik yasalarına göre, caveanın belirli kısımlarındaki nişler içerisine yerleştirilen bronz küplerin varlığını antik kaynaklar aracılığıyla biliyoruz. Ancak hala bu konuya dair kanıtlar yetersiz olup, tartışmalar devam etmektedir. Araştırmacılar bazı tiyatrolardaki (Aspendos, Beth Sean (İsrail) ve Selge Tiyatrosu vb.) nişlerin bu bronz küplerle alakalı olduğunu söylemektedir. Ayrıca bunun yanı sıra aydınlatmaya yönelik (Aspendos Tiyatrosu) olabileceği de düşünülmektedir. Yapılacak yeni tiyatro kazılarında bulunacak nişlerin içerisinde bronz bir küp kalıntısı ortaya çıkarılana kadar, bu tartışmaların devam edeceği açıktır. Tiyatro üzerini kapatarak insanları güneşten koruyan velumların, aslında sesin yankılanmasını önleyerek akustik anlamda fayda sağlamış olduğu düşünülür. Tiyatro yapımında kullanılan taşların bile (kireçtaşı, mermer, kalker vb.) akustik işlev görmüş olabileceği, çeşitli deneysel çalışmalarla ortaya konulmaya çalışıımıştır ${ }^{107}$. Tiyatro yapımında seçilen taşların öncelikle yapıya taşınmasının kolay olacağı en yakın yerden elde edilmesi düşünülmüş, maliyet konusu belki de ilk planda yer almıştır. Tiyatro inşası için seçilecek yapı malzemesinin (kireçtaşı, mermer, kalker vb.) seçiminde akustik nitelikler pek fazla dikkate alınmamıştır. Ancak yapılan deneysel çalışmalarla, tiyatronun ayrı ayrı bölümlerinde kullanılması için seçilen taş çeşitlerinin, dolaylı da olsa akustiği etkilediği görülmektedir. Roma tiyatro planının Hellenistik tiyatrolara göre daha kapalı olması, bu tiyatrolarda akustik parametrelerin daha ileri düzeye ulaşmasına imkân tanımıştır. Tiyatro oyunlarında aktörlerin kullandığı maskların megafon görevi yaparak sesin şiddetini yükselttiği, bunun sonucunda sesin izleyiciye daha rahat ulaştığı anlaşılmıştır.

Antikçağ tiyatrolarının ilk ortaya çıkışından itibaren gelişerek değişen formu, kullanılan yapı malzemesi, oturma sıralarının gelişimi, sahne binasının gelişim ve değişimi gibi gelişmeler tiyatrolardaki akustiğin zaman içerisinde iyileşmesine katkı sağlayan faktörlerdendir ${ }^{108}$. Akustik nitelik asla tek başına değerlendirilemez ${ }^{109}$. Çünkü yukarıda değinilen birçok faktörün birleşmesi ve gelişmesiyle meydana gelen akustik, işitsel bir olgudur. Kısacası, ortaya çıkışıla insanların bir arada olmasını, eğlenmesini, düşünmesini ve fikirlerini açıkça ortaya koyabilmesini sağlayan tiyatro, bir mimari yapı formuna dönüşmesiyle gelişen akustik özelliklerini, insana, kendini anlatma ve anlama çabası için sürekli geliştirmenin yollarını aratmıştır.

\footnotetext{
107 Declercq - Dekeyser 2007a; Declercq - Dekeyser 2007b.

108 Chourmouziadou - Kang 2008, 527.

109 Sabine 1922, 197.
} 


\section{BİBLIYOGRAFYA}

\section{Antik Kaynaklar}

Vitr. de Arch.

\section{Modern Literatür}

Aykol 1986

Bakım 2014

Barba Sevillano et al. 2008

Baysal 2015

Bingöl 2012

Boyacıŏlu 2004

Canac 1967

Chourmouziadou - Kang 2008

Çelgin 2011

Çetinkaya 2010

Çevik et al. 2012

Declercq - Dekeyser 2007a

Declercq - Dekeyser 2007b

Dragonetti et al. 2007

Dilmen 2004

Eagleson 1940

Er 2012

Erol 2006
(=Vitruvius, De Architectura)

Kullanılan Metin ve Çeviri: On Architecture, vols. I-II. Trans. F. Granger London -New York 1931-1934 (The Loeb Classical Library).

Vitruvius, Mimarlık Üzerine On Kitap. Çev. S. Güven, Ankara 1998.

E. Aykol, Eğitsel Iletişim Ortamlarında, Ses Boyutu ve Akustiğin İşlevi. Yayımlanmamış Doktora Tezi, Anadolu Üniversitesi. Eskişehir 1986.

S. Bakım, Fibonacci Dizisi ve Altın Oran'ın Müzikte Kullanımının Incelenmesi. Yayımlanmamış Yüksek Lisans Tezi, Selçuk Üniversitesi. Konya 2014.

A. Barba Sevillano- R. Lacatis- A. Giménez- J. Romero, "Acoustics vases in ancient theatres: disposition, analysis from the ancient tetracordal musical system". Proc. of Acoustics'08 (2008) 4155-4160.

O. Baysal, "Kanon'un Bölünümü" yazması ve Helenistik dönemde müzikbilim. International Journal of Human Science 12/1 (2015) 13501380.

O. Bingöl, Bu Koca Taşları Nasıl Iş̧lediler, Nasıl Kaldırdılar. Ankara 2012.

F. Boyacıoğlu, "Geleneksel Tiyatro ve Uyumsuzluk Tiyatrosu". Selçuk Üniversitesi Sosyal Bilimler Enstitüsü Dergisi 11 (2004) 205-219.

F. Canac, L'acoustique des Theatres Antiques. CNRS, Paris 1967.

K. Chourmouziadou - J. Kang, "Acoustic evolution of ancient Greek and Roman theatres". Applied Acoustics 69-6 (2008) 514-529.

G. Çelgin, Eski Yunanca-Türkçe Sözlük. İstanbul 2011.

A. Çetinkaya, Bazı Böcek Türlerinin Ses Analizleri ve Zirai Mücadelede Kullanılabilirliğinin Araştırılması. Yayımlanmamış Yüksek Lisans Tezi, Çukurova Üniversitesi. Adana 2010.

D. B. Çevik - E. G. Canbey - I. Taviloğlu, "Armoni Eğitimi Neden Zordur?". Balıkesir Üniversitesi Sosyal Bilimler Enstitüsü Dergisi 15/27 (2012) 69-83.

Nico F. Declercq - Cindy S. A. Dekeyser, "Acoustic diffraction effects at the Hellenistic amphitheater of Epidaurus: Seat rows responsible for the marvelous acoustics". J. Acoust. Soc. Am. 121/4 (2007) 2011-2022. Nico F. Declercq - Cindy S. A. Dekeyser, "The acoustics of the Hellenistic Theatre of Epidaurus: the important role of the seat rows". Canadian Acoustics/ Acoustique canadienne 35/3 (2007) 120-121.

Dragonetti, R., Ianniello, C., Mercogliano, F., Romano, R. D., "The Acoustics of Two Ancient Roman Theatres in Pompeii". 19. International Congress on Acoustics, 2-7 September 2007, Madrid.

H. Dilmen, Aspendos Antik Tiyatrosunun Mimari ve Akustik Özellikleri. Yayımlanmamış Yüksek Lisans Tezi, Yıldız Teknik Üniversitesi. İstanbul 2004.

H. V. Eagleson, "Architectural Acoustics". Phylon 1/1 (1940) 35-38.

Y. Er, Klasik Arkeoloji Sözlüğü. Ankara 2012.

H. B. Erol, lç Mekânda Malzeme Kullanımında Akustik Performans Kriterleri. Yayımlanmamış Yüksek Lisans Tezi, Mimar Sinan Güzel Sanatlar Üniversitesi. İstanbul 2006. 
Ferrero 2009

Fossum 1926

Grimal 2012

Haddad 2008

Irklı - Çalışkan 1990

Irklı-Eryıldız 2006

Karatağ 2013

Knapp 2007

Kontomoichos et al. 2014

Kurtay et al. 2008

Mutlu 2001

Özdilek 2011

Özdilek 2016

Polat 2012

Rindel 2008

Sabah 2013

Sabine 1922

Sağer - Sevgi 2011

Thorpe 2012

Tomlinson 2012

Waug 2000

Wycherley 1991

Vovolis 2009

Vovolis 2011
D. D. B. Ferrero, Batı Anadolu'nun Eski Çağ Tiyatroları. Çev. E. Özbayoğlu. İstanbul 2009.

A. Fossum, "Harmony in the Theatre at Epidauros". American Journal of Archaeology 30/1 (1926) 70-75.

P. Grimal, Mitoloji Sözlüğü Yunan ve Roma. İstanbul 2012.

N. A. Haddad, "Reviving the Architectural and Acoustical Theatre Heritage: the Role of ERATO Project". CSAAR 2008B (2008) 421-434.

D. Irklı - M. Çalışkan, "Acoustical Properties of Roman Theatre in Aspendos". IAPS 11 Culture-Space-History 4 (1990) 352-361.

D. Irklı-Eryıldız, "The Acoustic Properties of Ancient Theatres: Computer Simulation and Measurements". Eds. K. Dörtlük et al., III Uluslararası Likya Sempozyumu Sempozyum Bildirileri, 07-10 Kasım 2005, Antalya (2006), 281-299.

M. Karatağ, Klasik Arkeoloji Sözlüğü Yunan-Roma. Ankara 2013.

F. Knapp, Historic Structure Report The Hearst Greek Theatre. University of California Berkeley, California 2007.

F. Kontomichos - C. Papadakos - E. Georganti - T. Vovolis, "The sound effect of ancient Greek theatrical masks". The International Computer Music Conference (ICMC) 14-20 September 2014, Athens-Greece (2014) 1444-1452.

C. Kurtay - D. I. Eryıldız - G. U. Harputlugil, "Mimar Kemaleddin Salonu Akustik Performans Değerlendirmesi ve Performans İyileştirme Önerileri". Gazi Üniversitesi Mühendislik Mimarlık Fakültesi Dergisi 23/3 (2008) 557-568.

B. Mutlu, Mimarlık Tarihi Ders Notları. İstanbul 2001.

B. Özdilek, Rhodiapolis Tiyatrosu ve Lykia Tiyatroları. Yayımlanmamış Doktora Tezi, Akdeniz Üniversitesi. Antalya 2011.

B. Özdilek, "Lykia Tiyatrolarına Genel Bakış". Cedrus IV (2016) 139-185.

A. B. Polat, Tonal Armonide Gitar Müziği Odaklı Olarak Akorların Kuruluş ve Bağlantılarının Yapısal Özelliklerinin Incelenmesi. Yayımlanmamış Yüksek Lisans Tezi, Trakya Üniversitesi. Edirne 2012.

J. H. Rindel, "Roman Theatres and their Acoustics". Ed. F. Mossberg, Sounds of History, Report 6, Lund (2008) 30-42.

A. Sabah, Antik Çağ Konser Mekânlarından 20. yüzyıl Mekânsal Müzik Konser Salonlarına Müzik ve Mimarlık Iliş̧kisi, Yayımlanmamış Yüksek Lisans Tezi, Mimar Sinan Güzel Sanatlar Üniversitesi. İstanbul 2013.

W. C. Sabine, Collected Papers on Acoustics. London 1922.

T. Sağer - A. Sevgi, "Klasik Armoni Çözümlerinde Kullanılan Bas Şifreleme Yöntemleri ve Derece İsimlendirmeleri". Inönü Üniversitesi Sanat ve Tasarım Dergisi 1/1 (2011) 23-36.

M. Thorpe, Roma Mimarlığı. Çev. R. Akbulut. İstanbul 2012.

R. A. Tomlinson, Yunan Mimarlığı. Çev. R. Akbulut. İstanbul 2012.

A. Waugh, Klasik Müzik Dinlemede Yeni Bir Yol. İstanbul 2000.

R. E. Wycherley, Antik Çağda Kentler Nasıl Kuruldu?. Çev. N. Nirven N. Başgelen. İstanbul 1991.

T. Vovolis, Proposon, the acoustical mask in Greek Tragedy and in Contemporary Theatre. Stockholm 2009.

T. Vovolis, "Mask, Actor, Theatron and Landscape in Classical Greek Theatre". The Acoustics of Ancient Theatres Conference Patras, September 18-21 (2011). 
Vovolis 2012

Yaşaroğlu 2006

Yılmaz 2010

Yüksel et al. 2005
T. Vovolis, "Acoustical mask and sound aspects of ancient greek theatre". Classica-Revista Brasileira de Estudos Clássicos 25-1/2 (2012) 149-173.

K. Yaşaroğlu, Açıkhava Tiyatrolarının Akustik Açıdan Değerlendirilmesi: istanbul Cemil Topuzlu Açıkhava Tiyatrosu Örneği. Yayımlanmamış Yüksek Lisans Tezi, İstanbul Teknik Üniversitesi. İstanbul 2006.

Y. Yılmaz, Anadolu Antik Tiyatroları. İstanbul 2010.

Z. Yüksel - S. Erdoğan - R. Ayangil - R. Ünver - C. Binan - C. Can, “AudioVisual Conservation and Restitütion of The Ancient Theaters and Odea in Virtual Environment: Erato Research Project". Yıldız Teknik Üniversitesi Mimarlık Fakültesi e-Dergisi Megaron 1/1 (2005) 1-8. 